\title{
A Study of the Condition of Timber Production in Iran and the Expected Production Rate in the Next Decade
}

\author{
Kamran Adeli (Corresponding author) \\ Economy and Management Forest, University of Mazandaran \\ PB 737, Sari, Iran \\ Tel: 98-91-6367-5283Ｅ-mail: kamranadeli@yahoo.com
}

Ali Yachkaschi

Forest Policy and Management, University of Gottingen, Germany

Tel: 98-91-1152-3016

Soleiman Mohammadi Limaei

Department of Forestry, Faculty of Natural Resources, University of Guilan

P.O. Box 1144, Someh Sara, Iran

Tel: 98-91-1336-4599 E-mail: limaei@guilan.ac.ir

Asghar Fallah

Forest Biometry, University of Agricultural and Natural Resource Sari

PB 737, Sari, Iran

Tel: 98-91-1152-1896 E-mail: fallaha2007@yahoo.com

Received: November 28, $2011 \quad$ Accepted: December 20, $2011 \quad$ Published: January 1, 2012

doi:10.5539/jsd.v5n1p144 URL: http://dx.doi.org/10.5539/jsd.v5n1p144

\begin{abstract}
In countries with industrial forests, the first resource for providing domestic timber is their productive forests. Iran, a country that holds a few timber forests in the north, has implemented deterministic programming in the past few decades. Knowing the process of timber production in these forests and also the condition of these products that are affected by the above mentioned programming is very crucial. Therefore, the present study focuses on the timber production of Iran's northern forests in a 33-year period (from 1978 to 2010), using simple regression analysis and time series. The results of square regression analysis revealed that this process has a significant relationship with the years under study and shows inconsistent changes. Furthermore, the overall inflation in domestic market of Iran has the highest effect on the deterministic programming of its northern forests. To predict timber production in Iran Auto-regressive moving average process 1-2 was employed, verifying the fact that the production rate will decline to about 740 thousand cubic meters. If current trends and decline in timber production continue, Iran would become increasingly dependent on imported timber. To avoid such dependence, or at least reduce it, it is necessary to change the present programming system from deterministic to dynamic, taking into account the internal and external risks in timber market such as inflation and average timber price.
\end{abstract}

Keywords: Timber production, Time series analyses, Rial value, Dollar value, Production predict

\section{Introduction}

In the whole management system of a country, wood industry is considered to play a vital role in people's life. Forest resources and their related macro policies are the key factors of optimal management to achieve a sustainable production that is in line with the demand of timber market, known through economic analyses. 
Forest programming, especially to harvest timber, requires comprehensive knowledge of forest condition and economic situation of the market (Nanang, 2010). However, unfortunately, there are different statistics on the exploitation and forest industry in Iran. This is observable in different resources where the amount of harvest from northern forests of Iran varies; for example, 1.5 million cubic meters in years before 2005 (Asareh, 2008), 750 thousand cubic meters (Jalili et al., 2007) and 4 million cubic meters (Anonymous, 2006) in 2006. It is noteworthy that woodmen base their major policy makings on these very figures. This knowledge requires reliable data and appropriate techniques for each forest area so that in addition to full knowledge, optimal programming for their exploitation would become possible, especially for the coming years (Mohammadi Limaei, 2006; 2010; Kehinde, 2010).

However, in Iran, predicting timber price and harvesting volume is not based on new systematic approaches but is limited to submitting the volumetric statistics and Rial value; for instance, Abdollahpour et al. (2001) estimated the harvest amount of northern forests of Iran to be more than 44395972 cubic meters with the Rial value of 13320 billion Rials, from 1950 to 2000 (the annual average of 4.4 million cubic meters). Yachkaschi et al. (2009) stated that the Caspian forests are the only natural source of timber production in Iran. This source is capable of producing more than 900 thousand cubic meters timber per year, which can be increased to 2 million cubic meters through appropriate planning while preserving the ecological condition of these forests. Given that, it is a matter of discussion that, in Iran, where the only source of modern timber production is the northern forests, what has the timber production rate been, and what the production rate will be with regard to the past trends?

\section{The Field of Study and the Data}

The study area is limited to management, economy and macro policies of northern forests of Iran. Therefore, the present research focuses on the northern forests of Iran that are the only industrial forests of this country. In the past decades there used to be an exploitation of timber from over 2 million cubic meters per year, but currently it is just about 700 thousand cubic meters. These forests extend to about 1.9 million hectare, out of which just 1.2 million hectare has the capacity to be harvested. These forests have an average growth of 2 to 3 cubic meter per hectare and per year (Anonymous, 2004). The data about timber production were gathered from Iran's Forest, Rangelands and Watershed management Organizations, forest exploitation corporations, and Iran's president deputy planning. The present research studied a 33 year period, from 1978 to 2010 . The time series of the predicts were decided to be one decade, that is, to 2020 .

\section{Methodology}

In this part, after collecting raw data for forest wood products of northern Iran a series of conversions for each kind of product were done (the technical office of Forest, Rangelands and Watershed management Organizations, 2010). Adding up different products of each year, the total production rate per year was calculated in cubic meter. Furthermore, production process in the course of study, and also gross and net worth of Rial value (excluding inflation) and dollar value were calculated and presented in diagrams. Simple regression analysis was conducted to study the relation between production and the period under study. At first it was hypothesized that all variables were functions of time (1) and the relation between each variable and time was studied through simple regression analysis (2).

$$
Y=f(t)
$$

In this equation, $Y$ is the variable, and $f(t)$ is the function of time, i.e. year.

Therefore, through the second equation, simple regression analysis of variables and time was conducted.

$$
Y=\alpha+\beta x+\varepsilon
$$

In this equation, $Y$ is the variable, $\alpha$ is the constant factor, $\beta$ the time variable coefficient, $x$ the under

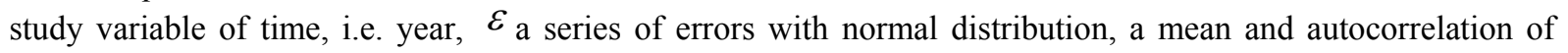
zero.

In case the equation with the variable of time is not significant, constant factor of $\alpha$ is omitted, the equation is expanded, and written in the form of a quadratic equation (3).

$$
Y_{t+1}=\alpha+\beta x_{t}+y x_{t-1}^{2}+\varepsilon
$$


In all these studies 5 indicators were used to show the significance and existence of a regression relation between the variables. At first, the value of $P$ indictor was studied, which was deemed to show a significant relation if it was less than 0.05 . There was also a comparison of statistical ${ }^{t}$ with the value of $t$ in the single side table by a probability of 95 percent, then its accuracy was examined. The other 3 indicators studied the amount of $R^{2}$, scatter plot points, and the obtained equation.

To predict the timber production rate, time series regression analysis was conducted. In fact, the presupposition for these series is the existence of periodic natural changes. However, before embarking on static time series tests, the correlation coefficient between two variables of the amount of data in the present $\left({ }^{t}\right)$ and a year before $(t-1)$ was calculated by means of SPSS software, and Pearson correlation coefficient. Then, to determine the static or non static status, choosing the appropriate differential phase (the first, second, or higher levels for eliminating the process effect), the 33-year data available, and $\alpha, \beta$ or other correlation coefficients between the present year and the past differential years were calculated. To this aim, two different methods were employed. First, by means of winSTAT lateral software that is installed on excel software, establishing regression between the appropriate current year and differential years data, independent variable coefficients such as $\alpha$, and $\beta$ are calculated for $t-1, t-2$, etc. If the absolute value of these coefficients were between 0 and 1, the static condition could be established. The other method is examining the independence of errors, where Durbin-Watson test is employed to study the relation between the errors in the year $\left.t^{(} e_{t}\right)$ and its previous year $\left({ }^{e_{t-1}}\right)$ (Momeni, 2010). If the number obtained for this index is between 1.5 and 2.5 , the assumption that there is no correlation between the errors is verified, and consequently the series are proved to be static. To identify the appropriate differential phase, the graphs of the residuals of each phase were plotted; in case the residuals enjoy appropriate distribution, and follow each other in moving to higher phases, the differential of the same phase is used. In fact, linear differential equations are employed. Equation 4 is an n-order linear differential equation with constant coefficients where $C_{i}{ }_{\text {, }}{ }_{،} i=0,1, \ldots$ are constant.

$$
C_{0} Z_{t}+C_{1} Z_{t-1}+C_{2} Z_{t-2}+\ldots+C_{n} z_{t-n}=e_{t}
$$

Moreover, the following step where done to determine the pattern and predict the values. 1- A first-degree differential was performed for eliminating the period 2- The model was selected by means of the software and saved on it. 3- Plotting $P A C F$ and $A C F$ graphs for the selected model. 4- Values were predicted in the form of graphs and data, for the next ten years. 5- $P A C F$ and $A C F$ graphs for residuals were plotted. If the model was selected carefully and accurately, they were placed in the appropriate position. 6- Two tests of $M c L e o d-L i$ and auto-regression regularity minimum AICC ( $A R$ model with a minimum of $A I C C$ ) were performed with their $p$-value reported.

\section{Results}

\subsection{Timber Production}

The production rate of different forest products in northern Iran during the past 33 years confirms that, in the first 18 years, the production rate experienced an ascending trend, reaching its peak, i.e. 1760164 cubic meters, in 1994. Whereas, in its following years it underwent a strongly descending trend, getting to the lowest point, i.e. 783817 cubic meters, in 1389 (Figure 1).

The results of changes in Rial value of the produced timber in Iran's northern forests showed that this value has always had an ascending trend, however, it strongly rises in the last years of each phase (Figure 2).

The study of the dollar value of products revealed that this value has always had the capacity of being increased; however, in 3 years of 1992, 2002, and 2008 due to an unprecedented and severe decline in the value of the Rial against the dollar, this value has undergone a severe decline, too (Figure 3).

\subsection{The Relationship between the Production of Domestic Timber and Year}

Linear polynomial regression (square) analysis through variant independent centralization method showed that there is a significant relationship between the production of domestic timber and year because the Pvalue is more than 0.05 and the statistical $t$ is higher than the $t$ in one side table for a probability 0.05 and a degree of freedom of 30 (Table 1). In figure 4, the graph of the residuals distribution, standardized against the calculated 
domestic timber production per year is presented. It signifies the lack of evaluate the equation of this production is written as $Y=184.144-0.00017($ year -73$)+0.0000065(\text { year }-73)^{2}$

\subsection{Time Series of Timber Production in Iran}

Calculating the correlation coefficient between two variables of timber production in the current year and the previous year, it was revealed that there is a good correlation between these variables, as the absolute value of this coefficient according to Spearman index is 0.870 , and it is significant at a confidence level of 0.01 (Table 2). After conducting two differential phases for timber production rate series, the residuals distribution graph get to a normal state. Therefore, $\alpha$ and $\beta$ coefficients should be studied in static tests (Figures 5 and 6).

To study the coefficients of $t$ and $t-1$ variables the multivariate regression test was employed, importing data through Enter method. The results showed that the absolute value of both $\alpha$ and $\beta$ coefficients that are related to timber production in the present year and last year with timber production in the second differential phase has been between 0 and 1 that is significant (Table 3). Therefore, the whole time series of timber production have been static, and it is possible to use different kinds of ARMA.

The results also indicated that the Durbin-Watson test is 1.940 for timber production in simultaneous cooperation. So, in this test, like the previous test, the static condition for both differential phases exists. To obtain a suitable pattern, conducting a differential phase, the effect of process is eliminated from timber production series in Iran (Figure 7). Furthermore, autocorrelation and partial autocorrelation coefficients graphs show that the proper pattern can be $A R M A_{(1,2)}$ or $A R M A_{(2,2)}$ (Figure 8).

Examining 13742 patterns, the output of ITSM2000 software was $X(t)=0.7804 X(t-1)+Z(t)-1.544 Z(t-1)+0.9997 Z(t-2)$ that is a $A R M A_{(1,2)}$ model. To confirm the accuracy of the model, $A C F$ and $P A C F$ graphs were plotted (Figure 9). As seen, the model and series coefficients correlate with each other. Using this pattern, the amount of produced timber in Iran is predicted for the next ten years (Figure 10). From predict it could be concluded that the rate of timber production in Iran would face a very mild decline in production and may get to about 741000 cubic meters (Table 4).

To examine residuals $A C F$ and $P A C F$ graphs were plotted. Since $A C F$ and $P A C F$ graphs follow their similar graph for the series, and are distributed proportionally (Figure 10), and the results of McLeod-Li test with a $P$-value of 0.028 is significant at 5percent, the present model can be considered as the best and most realistic model for timber production series in Iran.

\section{Discussion}

The study of a 33-year timber production in Iran corroborated that the production has first had an upward and then a downward trend that is inconsistent with those presented by Abdollahpour et al. (2001), Asareh (2007), Jalili et al. (2007), Anonymous (2006) and Hasmi et al. (2007). This is while the destruction of forests and their non-productivity have significantly increased. This fact confirms that, it is not the over-exploitation of Iran's northern forests but the methods of exploitation that leads to their destruction (Yachkaschi, 1968; 1975) and causes such crises. A closer scrutiny shows that, in these forests firewood has the highest rate of production which can be attributed to lack of optimal exploitation plans on the part of forest engineers. That is, for each cubic meter production of log and lumber, firewood production is about two times. This is consistent with the studies of Yachkaschi (1982), Ebrahemi (2008) and Saeed (1996). In Katin the supply is remarkably in line with the amount and use of its demand, and there is a balance in its market. Moreover, the amount of the coal produced in forests has declined significantly due to the decrease in the permits issued by the Forest, Rangeland, and Watershed management Organizations of the country, and substitution of fossil fuels for coal in urban and rural communities in Iran. This can be attributed to the shrinking demand and its uneconomic exploitation (Traverse become concrete and replace the wooden ones).

The rise in the gross Rial value of timber can be ascribed to Iran's excessively increased inflation rate that is still observable even with decline in production and net price of stock volume. Increase in slope signifies the inflation raise in timber production of Iran's northern forests. However, in the case of the dollar value of produced timber it can have a negative effect on timber import and the market, and cause great loss.

Considering the much higher production potential of northern forests of Iran, the low significance observed in the relation between timber production and the years under study verifies the inconsistency in the management and policy making of these forests. The incongruities in management methods and lack of long term recorded plans, changes the production rate and causes imbalance in the market. In fact, it can be claimed that currently 
there is no balance in the timber market, and this is the cause of market's preference for low quality goods or wood (poplar wood) instead of high quality ones (timber).

The model offered for timber production of Iran's northern forests is Auto-regressive moving average process 1-2. This is just because there has not been a specific procedure for timber production due to changes in the macro policies of the Forest, Rangelands and Watershed management Organizations. Regarding the actuality of the presented models, series of timber production in Iran have had a definite and actual status due to incidental circumstances and sudden losses that happen to the variables. In fact, different fluctuations during these years have led to offering more actual models for the predict, because the moving average time series which play a crucial role in each of these series are in charge of analyzing the data with sudden changes. Therefore through an appropriate retrogressive analysis and selecting longer time series, a more actual model can be suggested for them (Shoaibi et al., 2010). However, according to the present predictions, timber production in northern forests of Iran would decline about 5 percent, that is, 41997 cubic meters.

\section{Conclusion}

Timber production in northern forests of Iran considerably affects the timber market in this country. But unfortunately, during the past 70 years, there has been a definite and static plan for harvesting. However, the results of this study, especially the part that deals with the analysis of production series of different kinds of wood in this market, show that this method suffers from several shortcomings and weaknesses when it comes to application. This finding is in line with the studies of Yachkaschi (1982) and Johansson and Löfgren (1985). Frequent and sometimes illogical changes in the policies of timber harvest and its value certifies this claim. In addition, excessive production of firewood and inefficiency in harvest engineering confirms the deficiency of this programming. Since market demand for some products changes due to lack of customers and changes in public taste, we should employ more flexible programs to minimize the effect of principal economic factors such as inflation on the process of timber production. This policy makes the production process in northern forests of Iran more definite and predictable. It is conclusive that if no dynamic and flexible plan is implemented the prediction of decline in timber production will come true.

\section{References}

Abdollahpour, Mostafa \& Asadi atoie, Alireza. (2001). A study of forestry changes in Caspian forests (pp. 33). The publication of the Country's Forests and Rangelands Organization. [Online] Available: http://www.frw.org.ir/

Anonymous. (2004). The natural resources of Iran in past, present, and future (pp. 151). Monthly dam publication, agro-industry (appendix). Number 63.

Anonymous. (2006). Forestry community of Iran, Mazandaran branch, the necessity of establishing the supreme council of natural environment protection in Northern provinces of Iran (pp. 8). Monthly magazine of green nature.

Anonymous. (2006). Forestry community of Iran, Mazandaran branch, the necessity of establishing the supreme council of natural environment protection in Northern provinces of Iran (pp. 8-12). Monthly magazine of green nature.

Asareh, Mohammad Hassan. (2008). Wood agriculture through poplar planting, an urgent necessity for sustainable access to cellulosic materials (pp. 41-51). Proceedings of the second national conference on poplar and its significance in wood agriculture. First volume.

Ebrahimi, Ghanbar. (2008). Forest utilization management process and wastage (pp. 32-44). Proceedings of the first national conference on wood and paper industrial, Gorgan, Iran.

Hasmi, Amir hooman, Amiri, Saeed, Hamdi, Karim \& Ebrahimpor kasmani, Jafar. (2007). A study of different timber products in mazandaran province in a ten-year period (73-83). Journal of agricultural sciences, 13 (1), 237-253. [Online] Available: http://www.sid.ir/Fa/VEWSSID/J_pdf/53513860119.pdf

Jalili, Adel \& Hossini, Sadegh. (2007). The strategy of sustainable lingocellulosic materials in Iran (pp. 165). Research Institute of Forests and Range country. Project number 386. [Online] Available: http://www.rifr-ac.ir/

Johansson, P.O., Löfgren, K.G. (1985). The economics of forestry and natural resources (pp. 292). New York, USA: Basil Blackwell press. [Online] Available: http://www.sciencedirect.com/science/article/pii/037811279190248T 
Kehinde, A. L, Awoyemi, T. T, Omonona, B. T, Akande, J. A. (2010). Technical efficiency of sawnwood production in Ondo and Osun states, Nigeria. Journal of Forest Economics, 16, 11-18. http://dx.doi.org/10.1016/j.jfe.2009.04.001

Maarit, A. \& Kallio, I. (2010). Accounting for uncertainty in a forest sector model using Monte Carlo simulation. Forest Policy and Economics, 12, 9-16. http://dx.doi.org/10.1016/j.forpol.2009.09.014

Mohammadi Limaei \& Soleiman. (2006). Economically optimal values and decisions in Iranian forest management (Doctoral thesis, pp. 91). Dept. of Forest Economics, SLU. Acta Universitatis agriculturae Sueciae.

Mohammadi Limaei \& Soleiman. (2010). Mixed strategy game theory, application in forest industry. Forest Policy and Economics, 12, 527-531. http://dx.doi.org/10.1016/j.forpol.2010.06.009

Momeni, Mansur. (2010). Statistical analysis by SPSS (pp. 302). New book publication.

Nanang, David M. (2010). Analysis of export demand for Ghana's timber products: A multivariate co-integration approach. Journal of Forest Economics 16: 47-61. http://dx.doi.org/10.1016/j.jfe.2009.06.001

Saeed, Arastou. (1996). The economic-practical basis of forests organization (pp. 341). Tehran university publication.

Shoaibi, shaghayegh, alvaezin, heshmat, amiri, saeed \& shamekhi, taghi. (2010). The effects of changes in import tariff on wood smuggling in northern forests of Iran. Iranian Forest journal, 2 (1), 13-24. [Online] Available: http://www.isaforestry.ir/UploadedFiles/EBooks/PDFs/s58.pdf

Yachkaschi, Ali. (1967). Forstliche verhaeltnisse in Iran, probleme and losungs (pp. 178). Veraschlaege. Goettingen.

Yachkaschi, Ali. (1975). Socio-economic issues of forests in Iran (pp. 262). Tehran university publication. Yachkaschi, Ali. (1982). Forst und umwelt problem in Iran (pp. 180). Unniversity of Gotingenn.

Yachkaschi, Ali, Adeli, Kamran, Latefi, Hooman, Mohammadi Samani, kiumars \& seifollahian, Majid. (2009). Trends in Forest Ownership, Forest Resources Tenure And Institutional Arrangements: Are They Contributing To Better Forest Management and Poverty Reduction? A case study of I.R. Iran (pp. 42). FAO. Rome. [Online] Available: http://www.fao.org/forestry/16405-012dc89a33a412e50af12292bc4e7d7f6.pdf

William, W.S.V. (2007). The analysis of single variable and multivariable methods time series (2nd Ed., pp. 586). Translation: Hossein ali Niroumand, Ferdowsi university of Mashhad publication.

Table 1. ANOVA and significant coefficient regression of timber production with year

\begin{tabular}{ccccccc}
\hline Source of variations & Degree of freedom & Sum of squares & Mean of squares & $F$ & Pr & $R^{2}$ \\
\hline Regression & 2 & 1020.77 & 510.38 & 7.77 & $<0.0019$ & 0.3412 \\
Residual & 30 & 1971.23 & 65.71 & & & \\
Total & 32 & 2992 & & & & \\
\hline
\end{tabular}

Table 2. Result of calculating the correlation coefficient between two variables of timber production in the current year and the previous year

\begin{tabular}{cccc}
\hline & & $\begin{array}{c}\text { Timber production of year } \\
t-1\end{array}$ & $\begin{array}{c}\text { Timber production of year } \\
t\end{array}$ \\
\hline Timber production of year \\
$t-1$ & $\begin{array}{c}\text { Correlation } \\
\text { coefficient } \\
\text { Significant } \\
\text { Number }\end{array}$ & 1.000 & $0.870^{* *}$ \\
Timber production of year & $\begin{array}{c}\text { Correlation } \\
\text { coefficient } \\
\text { Significant } \\
\text { Number }\end{array}$ & 32 & 0.000 \\
& $0.870^{* *}$ & 32 \\
\hline
\end{tabular}

**: Significant of $0.01 \%$ level. 
Table 3. Estimate $\alpha$ and $\beta$ coefficients for timber production series

\begin{tabular}{|c|c|c|c|c|c|}
\hline \multirow{2}{*}{ Model } & \multicolumn{2}{|c|}{ Non standardized coefficients } & \multirow{2}{*}{$\begin{array}{c}\text { Standardized coefficients } \\
\text { Coefficient } \beta\end{array}$} & \multirow{2}{*}{$t$ Statistic } & \multirow{2}{*}{ significance } \\
\hline & $B$ & standard error & & & \\
\hline Stable & 160400.336 & 107455.004 & & 1.493 & 0.147 \\
\hline Production $t$ & 0.251 & 0.176 & 0.268 & 1.427 & 0.165 \\
\hline Production $t-1$ & 0.627 & 0.183 & 0.644 & 3.434 & 0.002 \\
\hline
\end{tabular}

Table 4. The amount of predicted produced timber in Iran at the next ten years

\begin{tabular}{ccccccccccc}
\hline & 2011 & 2012 & 2013 & 2014 & 2015 & 2016 & 2017 & 2018 & 2019 & 2020 \\
\hline $\begin{array}{c}\text { Timber } \\
\text { production } \\
\text { (cubic } \\
\text { meter) }\end{array}$ & 896810 & 870550 & 847920 & 828100 & 810490 & 794600 & 780060 & 766550 & 753870 & 741820 \\
\hline
\end{tabular}

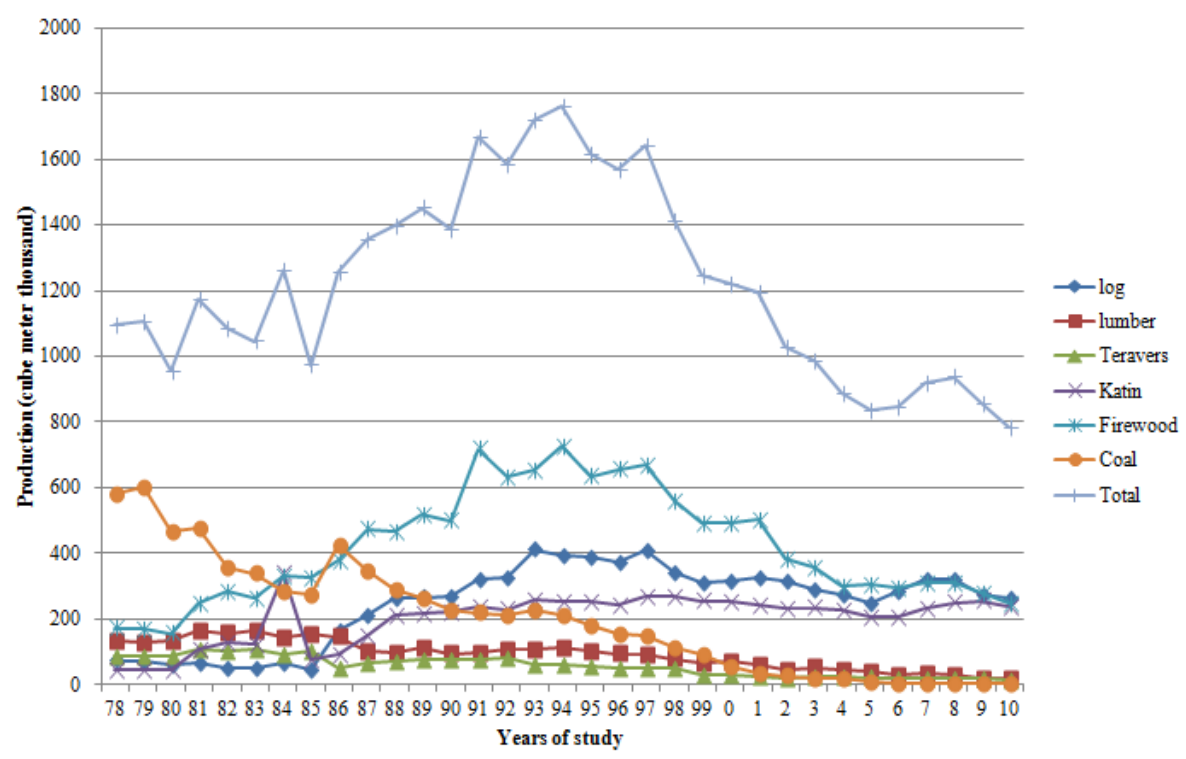

Figure 1. Total timber production and its different kinds in northern forests of Iran 


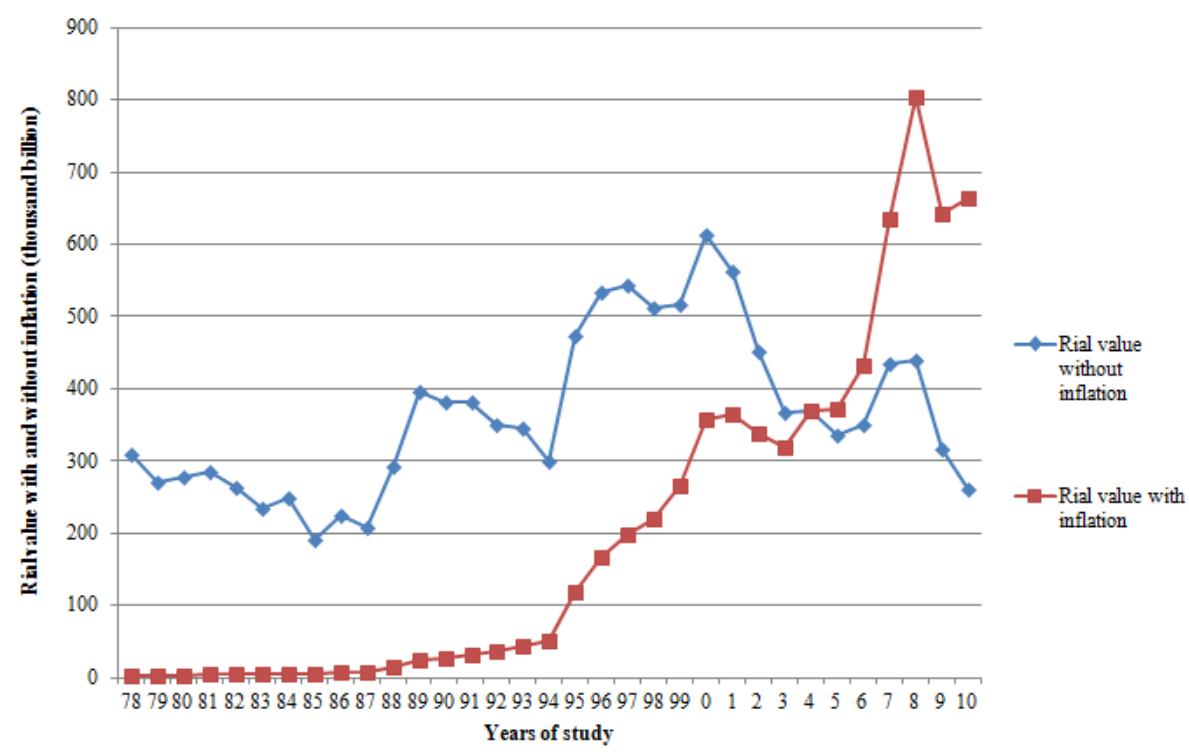

Figure 2. The Rial value of the total produced timber with and without inflation

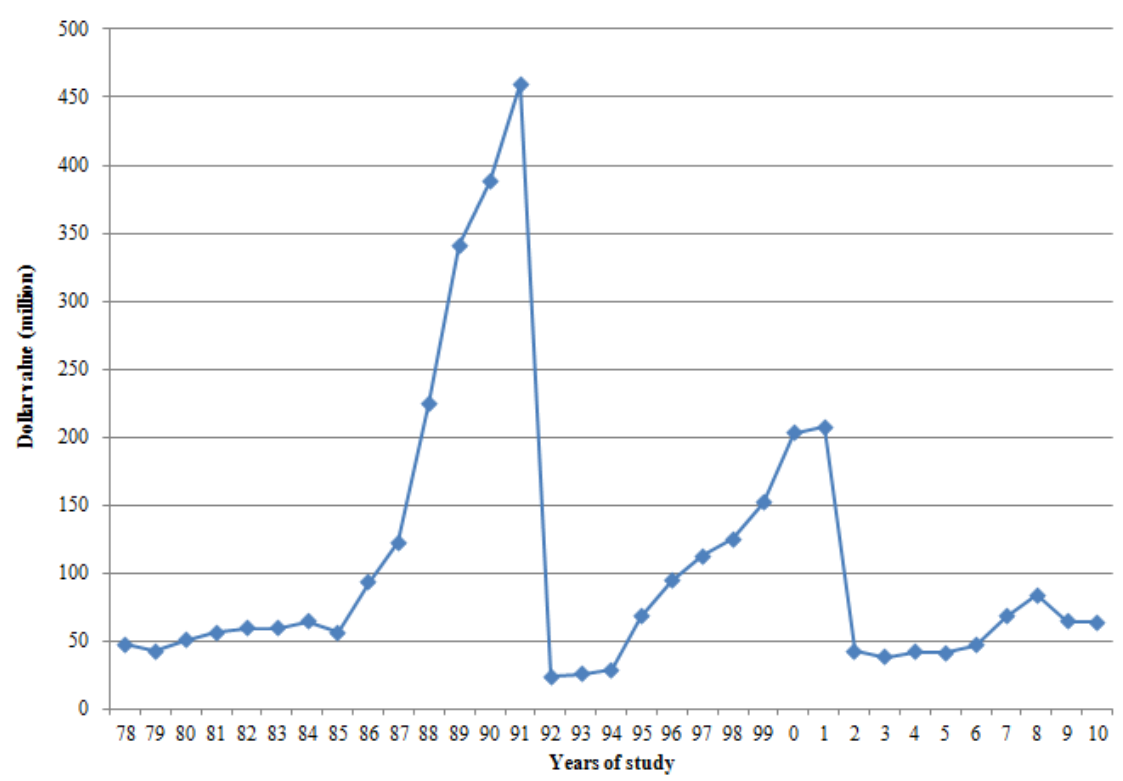

Figure 3. The dollar value of the produced timber in Iran 


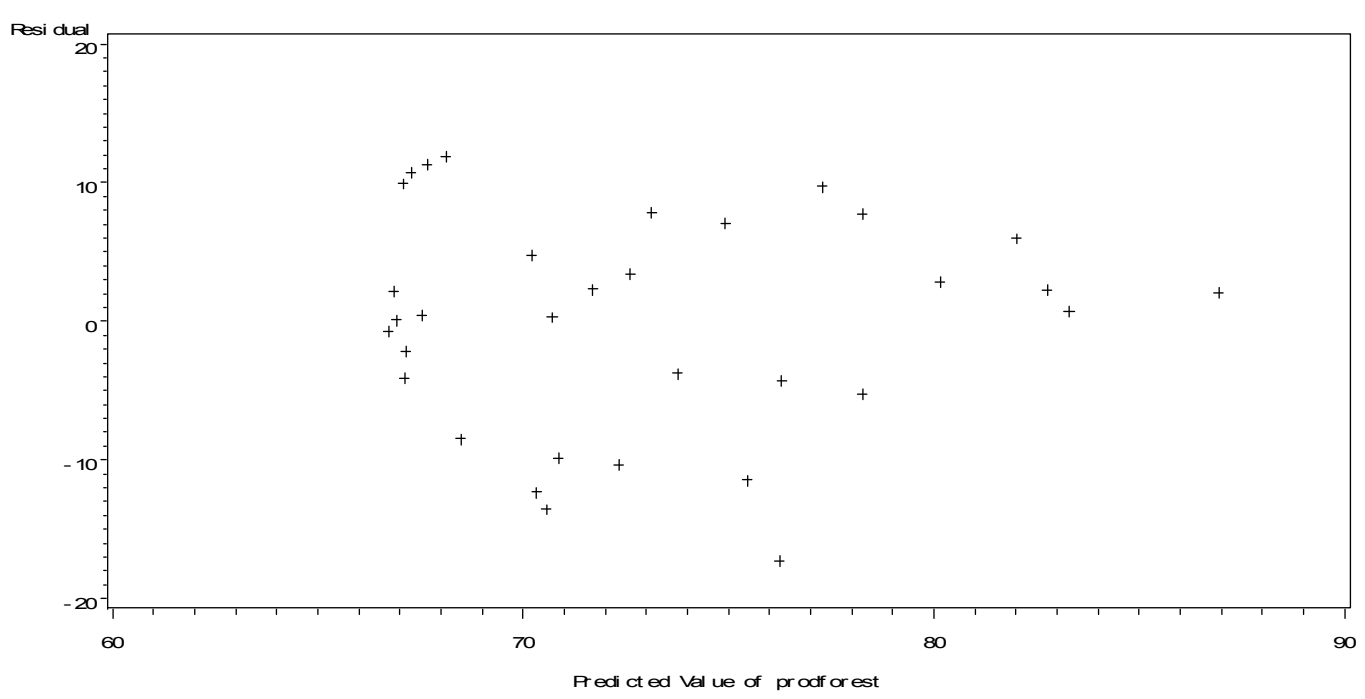

Figure 4. Graph of the residuals distribution domestic timber production per year

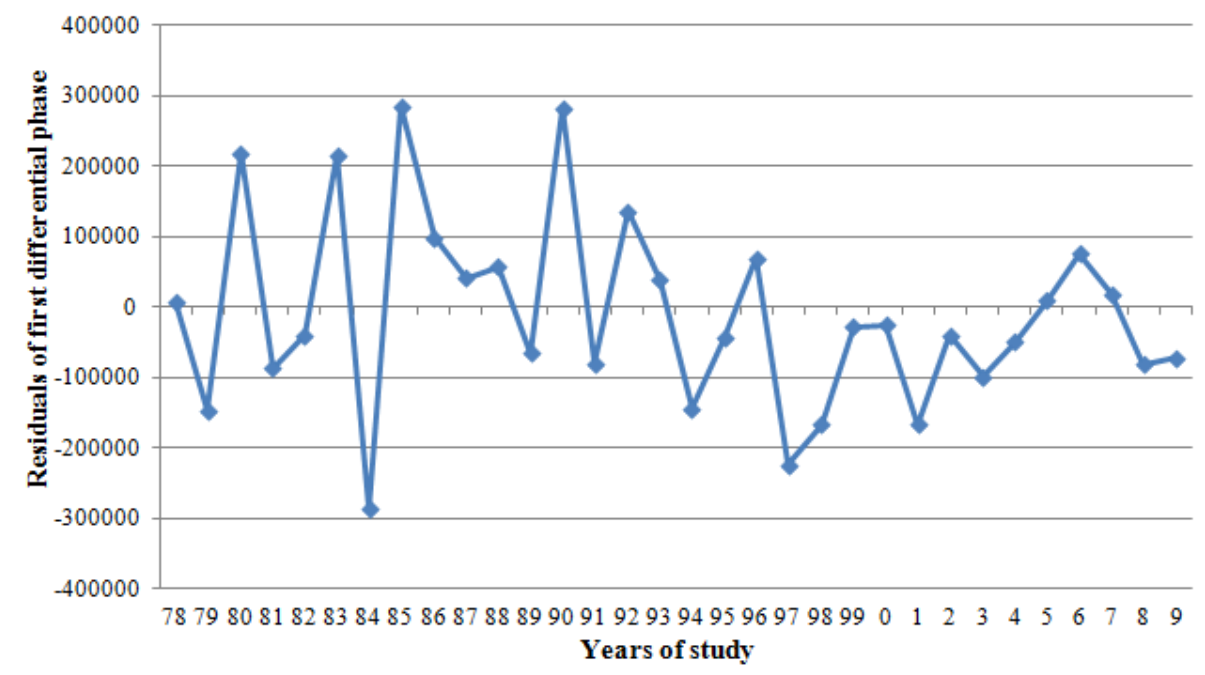

Figure 5. The first differential phase of timber production series 


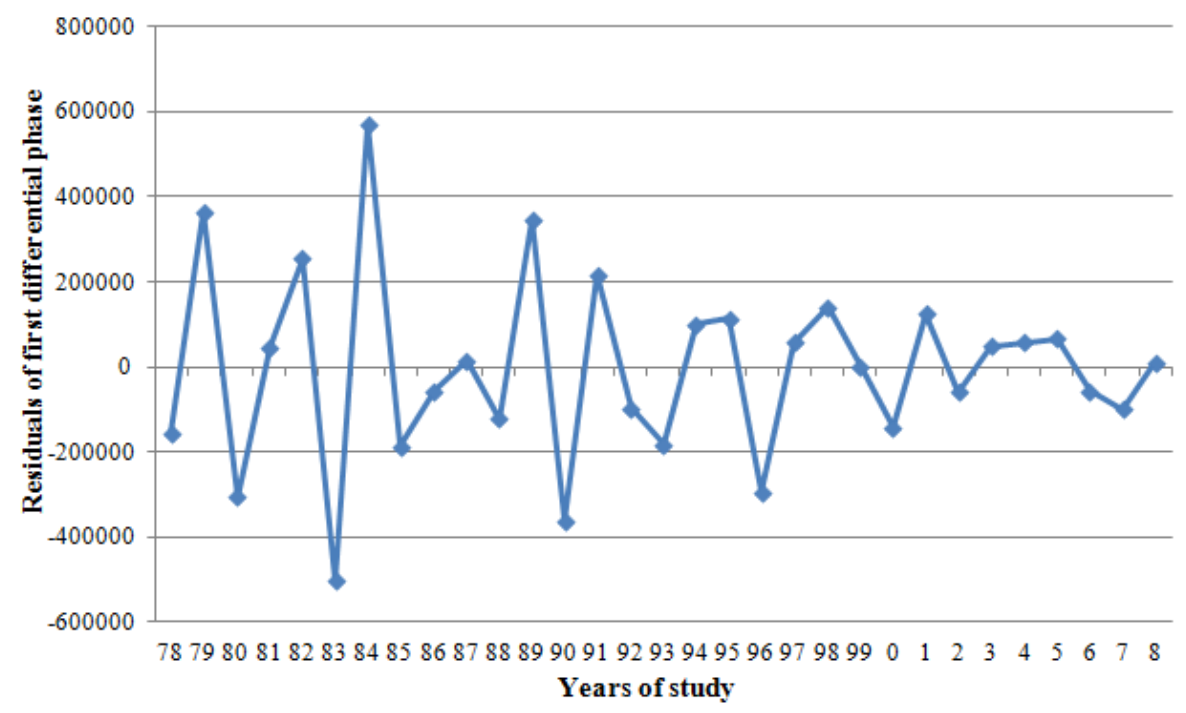

Figure 6 . The second differential phase of timber production series

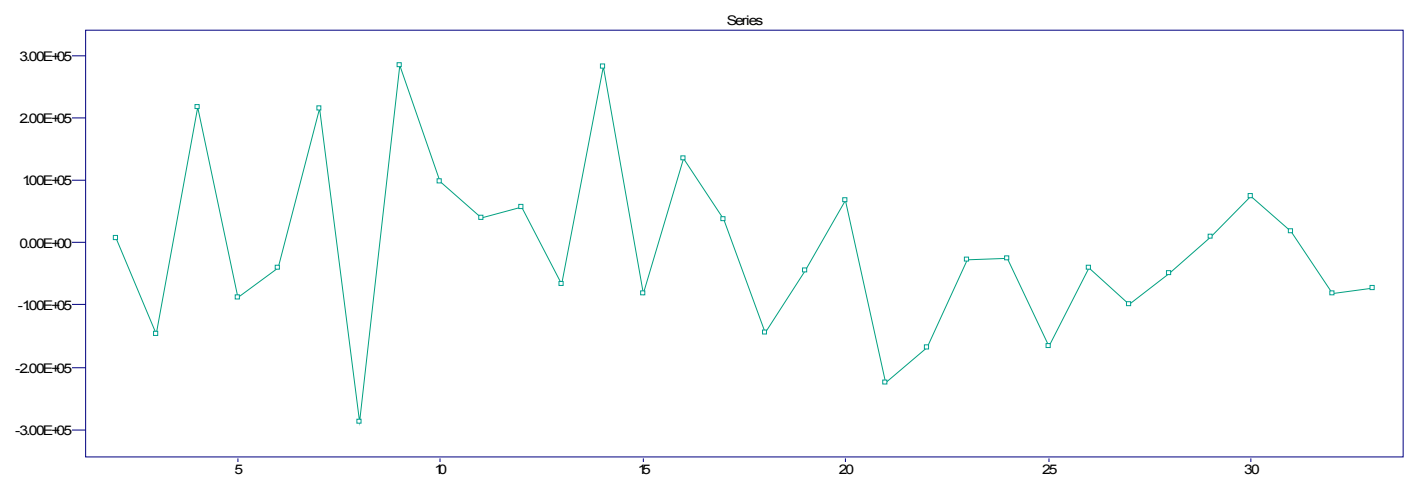

Figure 7. The first differential phase of timber production series after ARMA tests
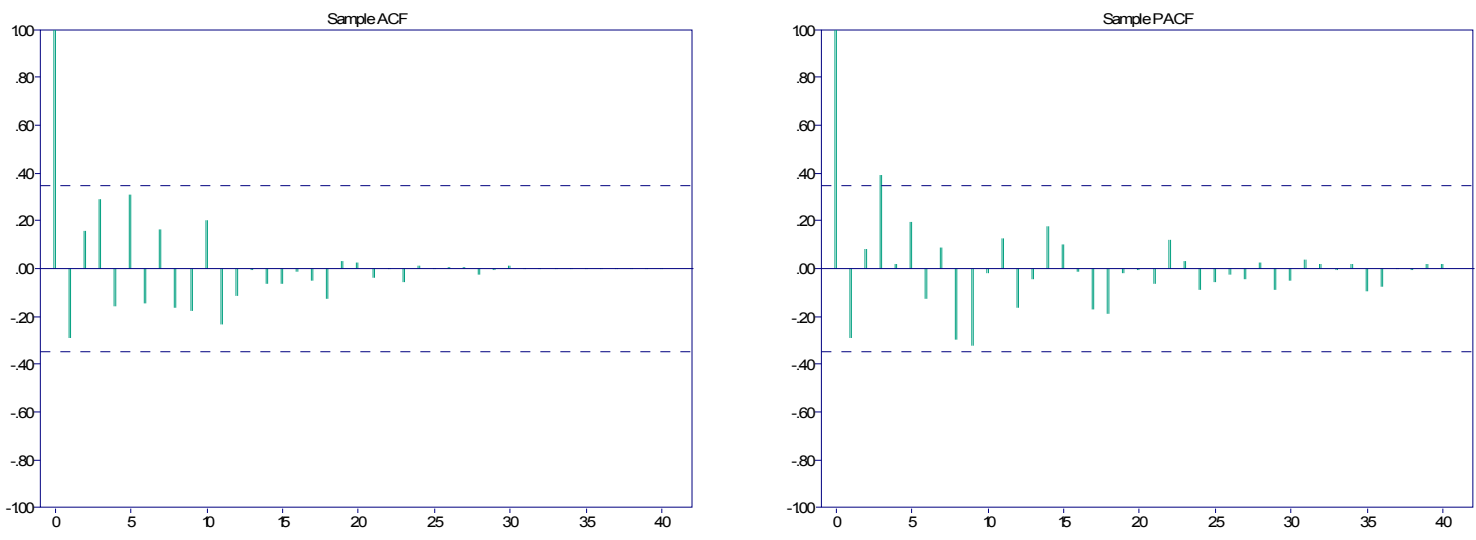

Figure 8. Autocorrelation and partial autocorrelation coefficients of timber production series 

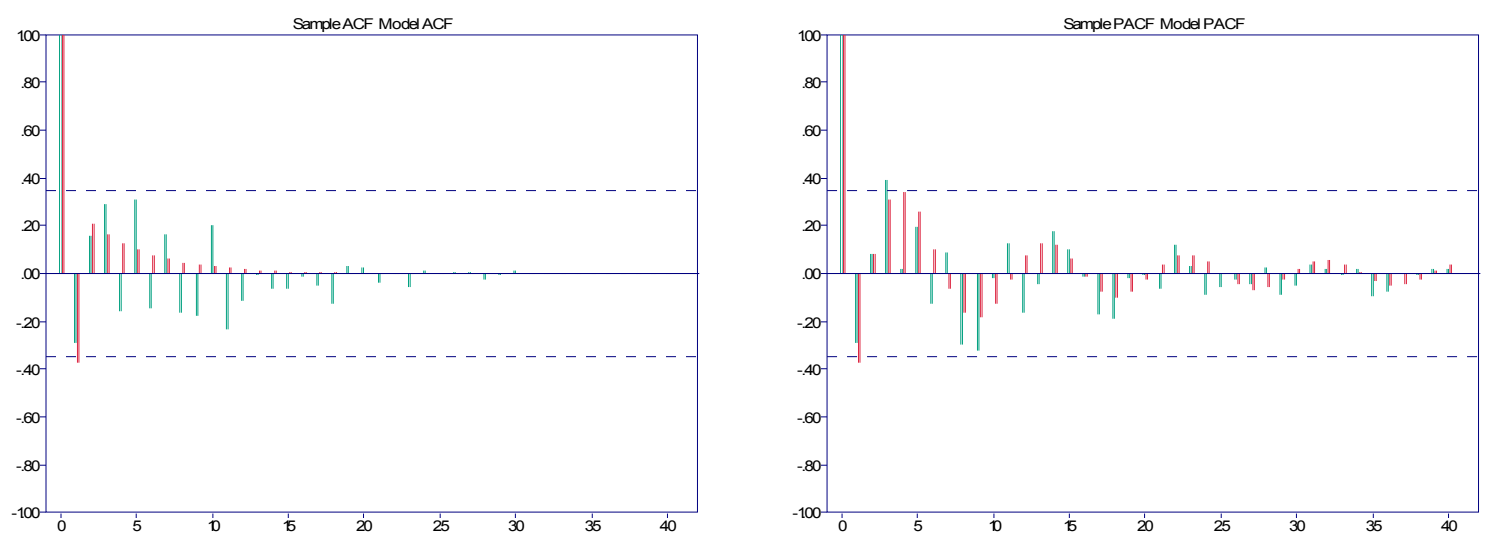

Figure 9. Autocorrelation and partial autocorrelation coefficients of timber production series after model selection

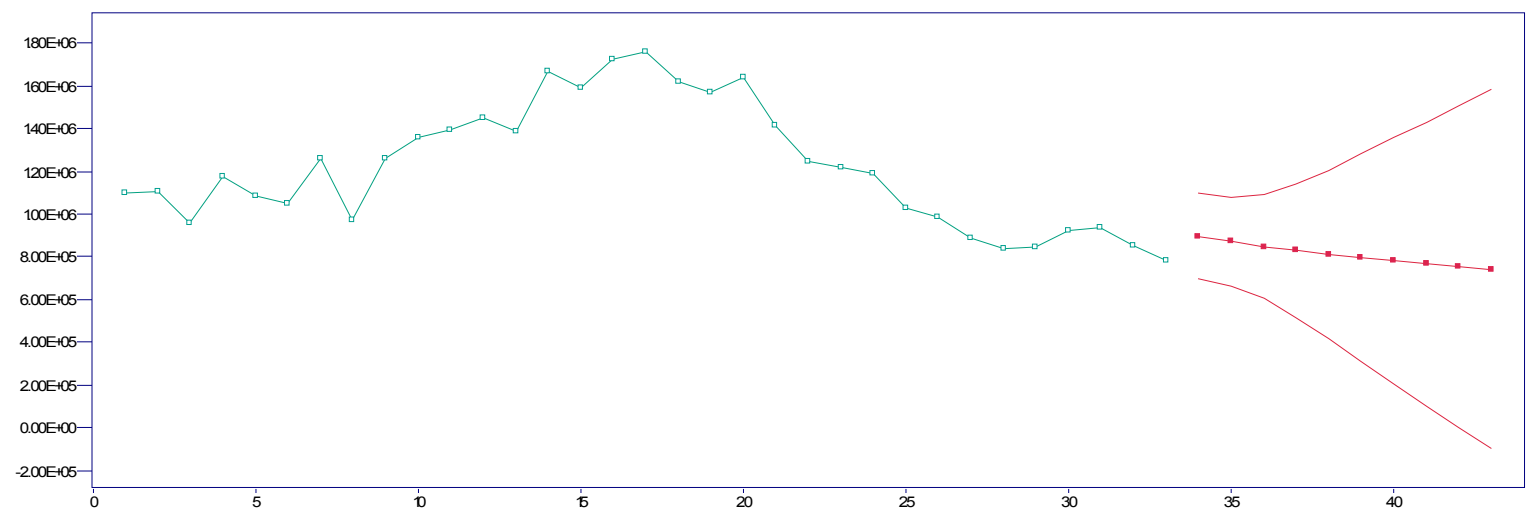

Figure 10. The predicted total domestic timber production in the next ten years 